\title{
Type II cGMP-dependent protein kinase inhibits activation of key members of the RTK family in gastric cancer cells
}

\author{
LU JIANG, YONGCHANG CHEN, JIANRONG SANG, YUEYING LI, \\ TING LAN, YING WANG, YAN TAO and HAI QIAN \\ Department of Physiology, School of Medical Science and Laboratory Medicine, \\ Jiangsu University, Zhenjiang, Jiangsu 212013, P.R. China
}

Received January 5, 2013; Accepted March 13, 2013

DOI: $10.3892 /$ br.2013.85

\begin{abstract}
Receptor tyrosine kinases (RTKs) are key to the regulation of biological cell activities, particularly of tumor cells. In a previous study, we demonstated that type II cGMP-dependent protein kinase (PKG II) may inhibit the activation of epidermal growth factor receptor (EGFR), a key member of the RTK family, and inhibit the consequent signal transduction in gastric cancer cells. Since RTKs exhibit a high level of conservation in their molecular structure, we hypothesized that PKG II may exert a similar inhibitory effect on the activation of other members of the RTK family. The aim of the present study was to investigate the potential inhibitory effect of PKG II on the activation of vascular endothelial growth factor receptor (VEGFR), platelet-derived growth factor receptor (PDGFR) and insulin-like growth factor-1 receptor (IGF-1R). The AGS gastric cancer cell line was transfected with adenoviral vector encoding PKG II cDNA (Ad-PKG II) to increase the expression of PKG II and incubated with 8-pCPT-cGMP to activate the kinase. The cells were then stimulated with VEGF, PDGF and IGF-1, and the phosphorylation/activation of relative RTKs was detected by western blot analysis. The results demonstrated that stimulating cells with VEGF-C $(100 \mathrm{ng} / \mathrm{ml})$, PDGF-BB (100 ng/ml) and IGF-1 (100 ng/ml) for $5 \mathrm{~min}$ led to a clear increase of phosphorylation of VEGFR2 (Tyr 951), PDGFR $\beta$ (Tyr 751) and IGF-1R (Tyr 1161), respectively. Pre-infection of the cells with Ad-PKG II with a multiplicity of infection (MOI) of $100 \%$ overnight and pre-incubation of cells with 8-pCPT-cGMP (100 and $250 \mu \mathrm{M}$ ) for $1 \mathrm{~h}$ efficiently inhibited the ligand-binding-induced phosphorylation/activation of the RTKs. PKG II also inhibited the MAPK/ERK- and PI3K-mediated signal transductions induced by VEGF-C, PDGF-BB and IGF-1. The results demonstrated that PKG II
\end{abstract}

Correspondence to: Professor Yongchang Chen, Department of Physiology, School of Medical Science and Medical Technology, Jiangsu University, 301 Xuefu Road, Zhenjiang, Jiangsu 212013, P.R. China

E-mail: ycchen54@ujs.edu.cn

Key words: type II cGMP-dependent protein kinase, receptor tyrosine kinases, inhibition, gastric cancer cells may exert a wide range of inhibitory effects on the activation of RTKs and provided further evidence to confirm PKG II as a tumor suppressor.

\section{Introduction}

Receptor tyrosine kinases (RTKs) are cell surface receptors with a high-affinity for growth hormones/factors and which bind the majority of identified tyrosine kinases of cells. RTKs commonly consist of a single subunit with three domains: an extracellular N-terminal, a single hydrophobic transmembrane-spanning and an intracellular C-terminal region. The intracellular C-terminal region contains a tyrosine kinase domain and a segment with multiple tyrosine sites for auto-phosphorylation. This component of RTKs exhibits the highest level of conservation and comprises catalytic domains responsible for the kinase activity of these receptors, which catalyses the tyrosine phosphorylation of RTKs as well as of their substrates. Ligand binding to the extracellular domain of RTKs induces a series of events including the formation of receptor dimers, activation of the tyrosine kinase, tyrosine phosphorylation of the receptor or the substrate of the kinase and consequent signaling (1-4).

RTKs have been shown to be key regulators of normal cell processes and to play a crucial role in the development and progression of various types of cancer. There are $>10$ classes of RTKs, of which the most intensively studied are: i) the epidermal growth factor receptor (EGFR) class: EGFR class has four structurally related RTKs designated as ErbB-1 through ErbB-4. Among these, ErbB-1 (EGFR) and ErbB-2 are found in numerous human cancers and their excessive signaling may be critical in tumor development and their malignant potential (5); ii) the vascular endothelial growth factor receptor (VEGFR) class: this RTK class is one of the main inducers of endothelial cell proliferation and permeability of blood vessels. VEGFR-1 and VEGFR-2 are the main members of this class (6). VEGFR-2 appears to mediate almost all the known cell responses to VEGF and accumulating data have shown that this kinase was closely associated with the metastasis of tumor cells by accelerating neovascularization (7); iii) the platelet-derived growth factor receptor (PDGFR) class: PDGFs and their cognate tyrosine kinase receptors are involved in multiple tumor-associated 
processes, including the autocrine growth stimulation of tumor cells, stimulation of tumor angiogenesis and recruitment and regulation of tumor fibroblasts (8); iv) the insulin-like growth factor-1 receptor class (IGF-1R): RTKs in this class stimulate growth in several different cell types, inhibit apoptosis, act as an intermediate in numerous growth hormone responses and stimulate the growth of certain types of cancer, including breast, prostate and lung cancer $(9,10)$. Since RTKs are closely associated with the biological activities of tumor cells, a wide range of inhibitory effects of RTK activation is likely to be of significance in tumor suppression.

Type II cGMP-dependent protein kinase (PKG II) is a serine-threonine kinase that is important in the regulation of cell proliferation and apoptosis (11-14). Of note, accumulating evidence has demonstrated that PKG II is a potential tumor suppressor. Swartling et al (15) reported that PKG II inhibited the proliferation of human neuroglioma cells and this inhibition was associated with a decrease of the expression of transcription factor Sox 9 and the phosphorylation of Akt. Wang et al (16) reported that PKG II regulated cell proliferation and differentiation in the colonic mucosa and suppressed the growth of colon cancer cells. Research data from our laboratory demonstrated that the expression and activity of PKG II in human gastric cancer cell lines was significantly lower compared to that of normal cells (17) and the increase of expression and activity of PKG II inhibited the proliferation of gastric cancer cell lines (18). Furthermore, we observed that PKG II inhibited EGF-induced signal transduction of several pathways by inhibiting the activation of EGFR $(19,20)$. Since RTKs share a high conservation in their structure and the kinase phosphorylating site-analyzing software predicted potential serine/threonine phosphorylation sites on certain RTKs, we hypothesized that PKG II may exert a similar inhibitory effect on the activation of other members of the RTK family. This study was designed to investigate the inhibitory effect of PKG II on the phosphorylation/activation of the VEGFR, PDGFR and IGF-1R classes of RTKs.

\section{Materials and methods}

Cell lines and reagents. The AGS human gastric cancer cell line was purchased from ATCC (ATCC ${ }^{\circledR}$ no: CRL-1793TM). Adenoviral vectors encoding $\beta$-galactosidase (Ad-LacZ) and PKG II (Ad-PKG II) were kind gifts from Dr Gerry Boss and Dr Renate Pilz, University of California, San Diego, USA. Dulbecco's Modified Eagle's Media (DMEM) and fetal calf serum (FCS) were purchased from Gibco (Grand Island, NY, USA). The antibody anti-PKG II was purchased from Abgent Biotechnology (San Diego, CA, USA). Goat anti- $\beta$-actin and mouse anti-p-ERK antibodies were obtained from Santa Cruz Biotechnology, Inc. (Santa Cruz, CA, USA). Rabbit anti-ERK antibody was obtained from Cell Signaling Technology, Inc. (Danvers, MA, USA). Rabbit anti-p-VEGFR2, rabbit anti-VEGFR2, rabbit anti-p-PDGFR $\beta$, rabbit anti-PDGFR $\beta$, rabbit anti-p-IGF-1R, rabbit anti-IGF-1R, rabbit anti-p-PI3K p85 and rabbit anti-PI3K p85 antibodies were purchased from Bioworld Technology (St. Louis Park, MN, USA). The horseradish peroxidase-conjugated secondary antibodies were purchased from Jackson ImmunoResearch Laboratories (West Grove, PA, USA). The cellular permeable cGMP analog 8-pCPT-cGMP was obtained from Calbiochem (San Diego,
CA, USA). Recombinant human VEGF-C, PDGF-BB and IGF-1 were obtained from Peprotech (Princeton, NJ, USA). Electrochemiluminescence (ECL) reagents were obtained from Millipore (Billerica, MA, USA). Other reagents used were of analytical grade.

Preparation of adenoviral vectors. 293A cells were transfected with adenoviral vector encoding cDNA of LacZ and PKG II and cultured for up to 10 days until CPE was detected. The cells and culture medium were collected and underwent three freezing-thawing cycles. The supernatants containing the adenoviruses (Ad-LacZ and Ad-PKG II) were used to infect new 293A cells to amplify adenoviruses. Amplified adenoviral preparations were titrated and the $\mathrm{pfu} / \mathrm{ml}$ was determined and maintained at $-80^{\circ} \mathrm{C}$ until use.

Cell culture and infection with adenoviral vectors. AGS cells were cultured in DMEM supplemented with 10\% FCS and maintained at $37^{\circ} \mathrm{C}$ in a humidified incubator with $95 \%$ air and $5 \% \mathrm{CO}_{2}$. The medium was changed every two days and the cells were sub-cultured at confluence. On the day prior to infection, cells were freshly planted at $70-80 \%$ confluence and transinfection was performed with a multiplicity of infection (MOI) of $100 \%$.

Western blot analysis. Proteins extracted from whole-cell lysates were separated by $10 \%$ SDS-PAGE and were transferred onto the PVDF membrane. The primary antibodies were incubated overnight at $4^{\circ} \mathrm{C}$ and incubated with the corresponding secondary antibodies for $1 \mathrm{~h}$ at RT, with three washes following each incubation. ECL reagents were used to demonstrate the positive bands on the membrane.

\section{Prediction of PKG II-specific serinelthreonine phosphorylation} sites on RTKs. Protein phosphorylation site program GPS2.0 was used to indicate the potential PKG II-specific Ser/Thr phosphorylation site on the RTKs. The results demonstrated that the RTKs investigated in this study possessed potential serine/threonine phosphorylation sites. This observation suggested that PKG II affects the activation of these RTKs by phosphorylating specific Ser/Thr site on the receptors (Table I).

\section{Results}

PKG II inhibits the activation of VEGFR. Two membrane receptors exhibited a high affinity for VEGF: VEGF-R1 and VEGF-R2. In response to VEGF binding, VEGF-R2 underwent auto-phosphorylation on multiple tyrosine residues including Tyr 951, 996, 1054 and 1059. Since the phosphorylated sites were involved in the regulation of kinase activity, the phosphorylation of these sites represented the activation of VEGF-R2. In this experiment, western blot analysis with anti-phospho-VEGFR2 (Tyr 951) antibody was used to detect the phosphorylation/activation of VEGF-R2. AGS cells were infected with adenoviral vector encoding LacZ or PKG II overnight, treated with 8-pCPT-cGMP for $1 \mathrm{~h}$ and then with $100 \mathrm{ng} /$ $\mathrm{ml} \mathrm{VEGF-C} \mathrm{for} 5 \mathrm{~min}$. The cell lysate was subjected to western blot analysis. The result demonstrated that VEGF treatment led to a clear increase of Tyr 951 phosphorylation on VEGFR2, while PKG II effectively prevented the phosphorylation (Fig. 1). 
Table I. Potential serine/threonine phosphorylation sites of selected RTKs.

\begin{tabular}{|c|c|c|c|}
\hline RTK & Phosphorylation site & Kinase & Related AA sequence \\
\hline \multicolumn{4}{|c|}{ PDGFR $\beta$} \\
\hline & $180 \mathrm{~S}$ & AGC/PKG/PKG2 & YDHQRGFSGIFEDRS \\
\hline & $644 \mathrm{~S}$ & AGC/PKG/PKG2 & LKSTARSSEKQALMS \\
\hline & $651 \mathrm{~S}$ & AGC/PKG/PKG2 & SEKQALMSELKIMSH \\
\hline & $713 \mathrm{~S}$ & AGC/PKG/PKG2 & SDKRRPPSAELYSNA \\
\hline & $749 \mathrm{~S}$ & $\mathrm{AGC} / \mathrm{PKG} / \mathrm{PKG} 2$ & MDMSKDESVDYVPML \\
\hline & $856 \mathrm{~S}$ & AGC/PKG/PKG2 & ARDIMRDSNYISKGS \\
\hline & $863 \mathrm{~S}$ & AGC/PKG/PKG2 & SNYISKGSTFLPLKW \\
\hline \multicolumn{4}{|c|}{ VEGFR2 } \\
\hline & $393 \mathrm{~T}$ & AGC/PKG/PKG2 & MEVSERDTGNYTVIL \\
\hline & $439 \mathrm{~T}$ & AGC/PKG/PKG2 & VDSYQYGTTQTLTCT \\
\hline & $1231 \mathrm{~S}$ & AGC/PKG/PKG2 & LQNSKRKSRPVSVKT \\
\hline \multicolumn{4}{|c|}{ IGF-1R } \\
\hline & $5 \mathrm{~S}$ & AGC/PKG/PKG2 & ***MKSGSGGGSPTS \\
\hline & $293 \mathrm{~S}$ & AGC/PKG/PKG2 & LSAESSDSEGFVIHD \\
\hline & $316 \mathrm{~S}$ & AGC/PKG/PKG2 & SGFIRNGSQSMYCIP \\
\hline & $398 \mathrm{~S}$ & AGC/PKG/PKG2 & RHSHALVSLSFLKNL \\
\hline & $473 \mathrm{~S}$ & AGC/PKG/PKG2 & TGTKGRQSKGDINTR \\
\hline & $871 \mathrm{~S}$ & AGC/PKG/PKG2 & MYEIKYGSQVEDQRE \\
\hline
\end{tabular}

RTK, receptor tyrosine kinase; PDGFR $\beta$, platelet-derived growth factor receptor $\beta$; VEGFR2, vascular endothelial growth factor receptor; IGF-1R, insulin-like growth factor-1 receptor.

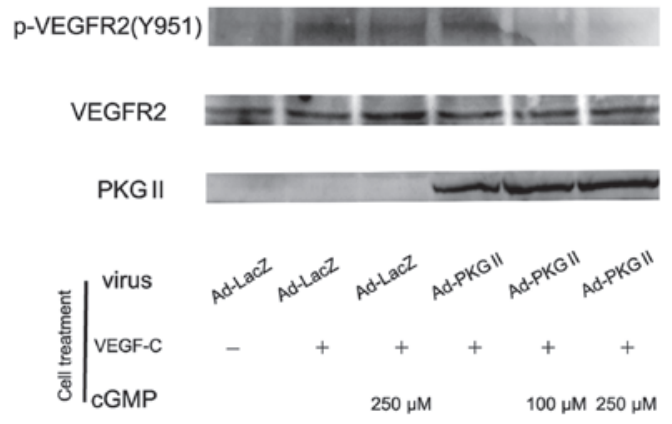

Figure 1. Type II cGMP-dependent protein kinase (PKG II) prevents vascular endothelial growth factor (VEGF)-C-induced Tyr 951 phosphorylation of VEGF receptor (VEGFR)2. AGS cells were infected with Ad-LacZ or Ad-PKG II for $48 \mathrm{~h}$ and serum-starved overnight for $14 \mathrm{~h}$. In Ad-LacZ + VEGF-C and Ad-PKG II + VEGF-C groups, cells were incubated with VEGF-C (100 ng/ml) for $5 \mathrm{~min}$. In Ad-LacZ + cGMP + VEGF-C and Ad-PKG II + cGMP + VEGF-C groups, cells were treated with 8-pCPT-cGMP for $1 \mathrm{~h}$ and then with VEGF-C $(100 \mathrm{ng} / \mathrm{ml})$ for $5 \mathrm{~min}$. The cells were harvested and lysed as described in Materials and methods and the cell lysate was subjected to western blot analysis. The infection with Ad-PKG II led to a clear increase of PKG II expression (Ad-PKG II groups). VEGF-C treatment induced a marked increase of Tyr 951 phosphorylation of VEGF-R2 (Ad-LacZ + VEGF-C group). Infection with Ad-PKG II + cGMP treatment effectively inhibited the VEGF-C-induced phosphorylation of VEGF-R2 (Ad-PKG II + cGMP + VEGF-C groups). The results shown are representative of three separate experiments.

PKG II inhibits the activation of PDGFR. The PDGF molecule consists of two amino acid chains that dimerize to form PDGF-AA, PDGF-AB and PDGF-BB. These functionally distinct isoforms may bind to the receptors PDGFR $\alpha$ and PDGFR $\beta$, leading to their phosphorylation. We performed

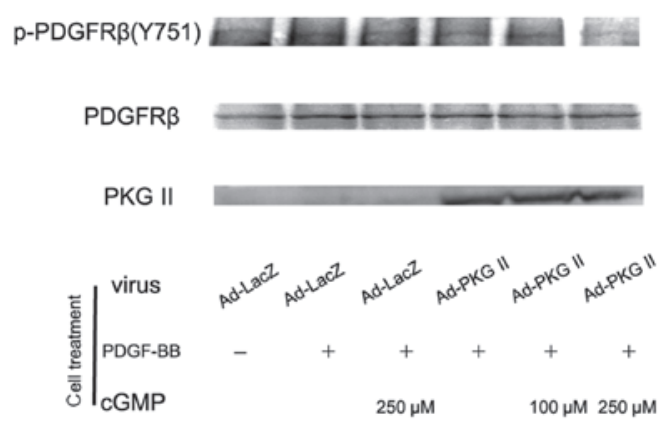

Figure 2. Type II cGMP-dependent protein kinase (PKG II) inhibited platelet-derived growth factor (PDGF)-BB-induced Tyr 751 phosphorylation of PDGF receptor (PDGFR) $\beta$. AGS cells were treated as described in Fig. 1, except that VEGF-C was replaced with PDGF-BB $(100 \mathrm{ng} / \mathrm{ml})$. Western blot analysis was applied to detect the Tyr 751 phosphorylation of PDGFR $\beta$. PDGF-BB treatment induced a marked increase of phosphorylation of PDGFR $\beta$ (Ad-LacZ + PDGF-BB group). Infection with Ad-PKG II and cGMP treatment effectively inhibited the PEGF-BB-induced phosphorylation of PDGFR $\beta$ (Ad-PKG II + cGMP + PDGF-BB groups). The results shown are representative of three separate experiments.

western blot analysis with antibody against p-PDGFR $\beta$ (Tyr 751) to detect the activating effect of PDGF-BB on PDGFR $\beta$ and the inhibitory effect of PKG II on this action. AGS cells were treated as described above and western blot analysis with anti p-PDGFR $\beta$ (Tyr 751) was performed. The results demonstrated that stimulating with PDGF-BB (100 ng/ $\mathrm{ml}$ ) for $5 \mathrm{~min}$ led to a significant increase of Tyr 751 phosphorylation on PDGFR $\beta$. Pre-infection with Ad-PKG II and treatment with 8-pCPT-cGMP effectively inhibited the phosphorylation/ activation of PDGFR $\beta$ induced by PDGF-BB (Fig. 2). 


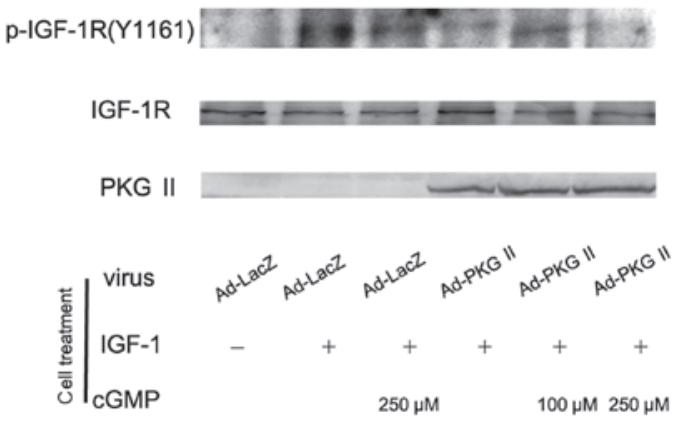

Figure 3. Type II cGMP-dependent protein kinase (PKG II) inhibits insulin-like growth factor (IGF)-1-induced Tyr 1161 phosphorylation of IGF-1 receptor (IGF-1R). AGS cells were treated as described in Fig. 1, except that vascular endothelial growth factor-C was replaced with IGF-1 $(100 \mathrm{ng} / \mathrm{ml})$. Western blot analysis was used to detect the Tyr 1161 phosphorylation of IGF-1R. IGF-1 treatment caused clear increase of the Tyr 1161 phosphorylation of IGF-1R (Ad-LacZ + IGF-1 group) and the increase of PKG II activity prevented the IGF-1-induced phosphorylation of IGF-1R (Ad-PKG II + cGMP + IGF-1 groups). The results shown are representative of three independent experiments.

$P K G$ II inhibits the activation of IGF-1R. There are two types of IGF receptors based on their relative affinities, IGF-1 and IGF-2. IGF-1 receptor (IGF-1R) consists of two $\alpha$ subunits and two $\beta$ subunits and is therefore preferred over IGF-2. In response to ligand binding, the $\alpha$ chain induces tyrosine autophosphorylation of the $\beta$ chain. This event triggers a cascade of intracellular signaling. Thus, the tyrosine phosphorylation of the $\beta$ subunit represents the activation of IGF-1R. In this experiment, AGS cells were infected with Ad-PKG II, treated with 8-pCPT-cGMP and stimulated with IGF-1 (100 ng/ml) respectively as described above. Western blot analysis with antibody against Tyr 1161 phosphorylated IGF-1R was employed to investigate the inhibitory effect of PKG II on the IGF-1-induced activation of IGF-1R. The results showed that IGF-1 treatment caused Tyr 1161 phosphorylation on IGF-1R and PKG II prevented the process (Fig. 3).

PKG II inhibits the ERK activation induced by VEGF, $P D G F$ and IGF-1. Activation of RTK initiates several signal transduction pathways. Of these the MAPK/ERK-mediated pathway is the one closely associated with cell proliferation and differentiation. Tyrosine phosphorylated RTKs are able to recruit the adaptor protein to phosphorylated sites and trigger a serine/threonine kinase cascade to phosphorylate ERK. Phosphorylation at Thr185 and 204 is required for the activation of ERK. Studies have shown that VEGF, PDGF and IGF are able to induce the activation of MAPK/ERK $(21,22)$. In this experiment, western blot analysis with anti phospho-ERK antibody was employed to detect the activation of this signal component induced by VEGF, PDGF and IGF-1 and the inhibition of PKG II on this activation. The results showed that $100 \mathrm{ng} / \mathrm{ml}$ of VEGF-C, PDGF-BB and IGF-1 caused phosphorylation/activation of ERK and PKG II prevented their phosphorylation/activation (Fig. 4).

PKG II inhibits the activation of PI3K induced by VEGF, $P D G F$ and IGF-1. The PI3K-mediated pathway is another signal transduction pathway that can be activated by tyrosine kinase receptors and is responsible for the production of lipids $\mathrm{p}-\mathrm{ERK} 1 / 2(\mathrm{Y} 204) \cong=\mathrm{E}=$

ERK1/2

PKG ॥

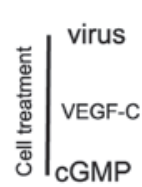

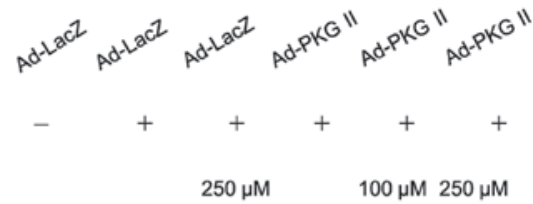

B

p-ERK1/2(Y204)

ERK1/2

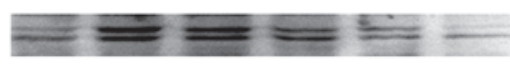

PKG II

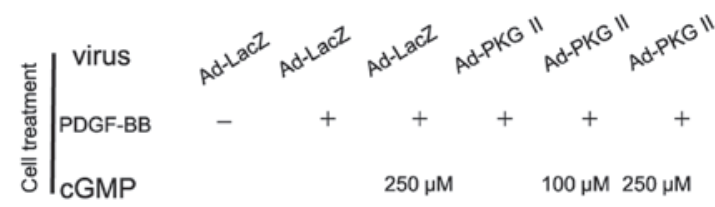

$C_{\text {p-ERK1/2(Y204) }}$

ERK1/2
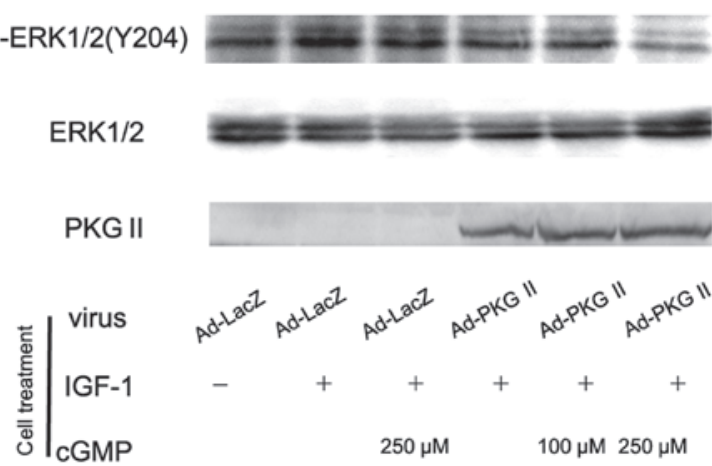

Figure 4. Type II cGMP-dependent protein kinase (PKG II) blocks Tyr 204 phosphorylation of ERK1/2 induced by vascular endothelial growth factor (VEGF)-C,platelet-derived growth factor(PDGF)-BB and insulin-like growth factor (IGF)-1 respectively. AGS cells were infected with Ad-PKG II for $48 \mathrm{~h}$, serum starved overnight for $14 \mathrm{~h}$, incubated with 8-pCPT-cGMP for $1 \mathrm{~h}$ and then stimulated with VEGF-C (100 ng/ml), PDGF-BB (100 ng/ml) and IGF-1 $(100 \mathrm{ng} / \mathrm{ml})$ respectively for $5 \mathrm{~min}$. Western blot analysis was used to detect the phosphorylation of ERK1/2. Within 5 min after adding the growth factors to culture medium, phosphorylation of ERK1/2 (Tyr 204) increased significantly (panel A, Ad-LacZ + VEGF-C group; panel B, Ad-LacZ + PDGF-BB group; panel C, Ad-LacZ + IGF-1 group) and the phosphorylation was inhibited by pre-infecting the cells with Ad-PKG II and stimulating the enzyme with 8-pCPT-cGMP (panel A, Ad-PKG II + cGMP + VEGF-C groups; panel B, Ad-PKG II + cGMP + PDGF-BB groups; panel C, Ad-PKG II + cGMP + IGF-1 groups). The results shown are representative of three separate experiments.

with biological activity. PI3Ks are composed of a catalytic (p110) and a regulatory subunit. Various isoforms of the catalytic subunit (p110 $\alpha, \mathrm{p} 110 \beta, \mathrm{p} 110 \gamma$ and $\mathrm{p} 110 \delta$ ) have been isolated. $\mathrm{p} 85 \alpha$ and $\mathrm{p} 85 \beta$ are the regulatory subunits that associate with $\mathrm{p} 110 \alpha, \mathrm{p} 110 \beta$ and $\mathrm{p} 110 \delta$. Upstream signaling causes the phosphorylation of $\mathrm{p} 85$ subunit of PI3K. In this experiment, western blot analysis with anti p85 (Tyr 458) antibody was applied to detect the phosphorylation of p 85 induced by 
A

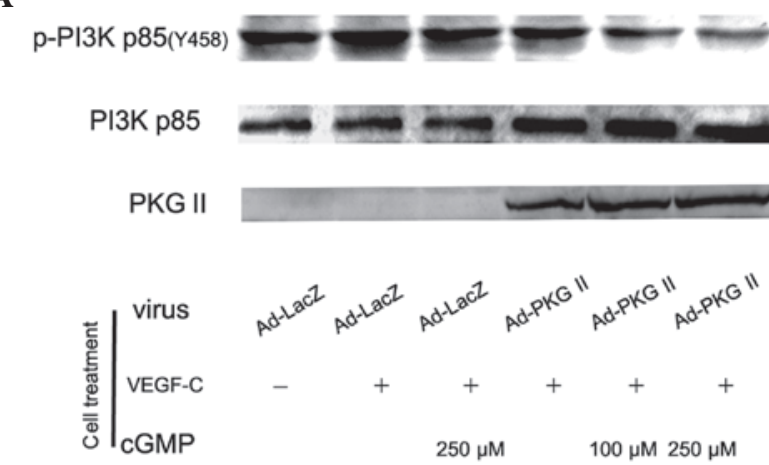

B

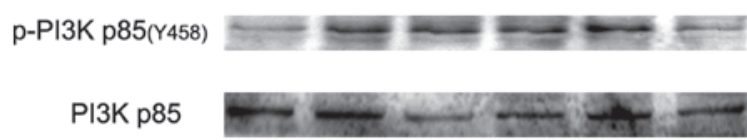

PKG ॥

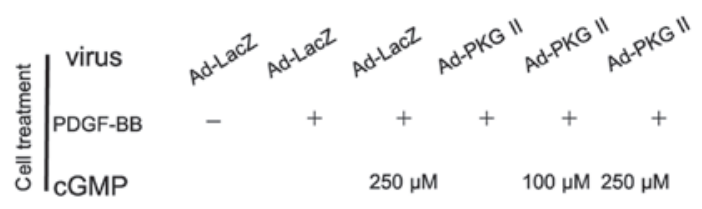

C

p-PI3K p85(Y458)

PI3K p85
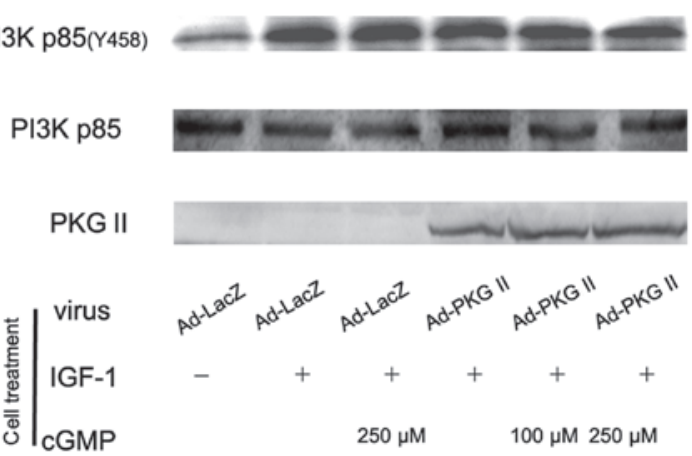

Figure 5. Type II cGMP-dependent protein kinase (PKG II) prevents Tyr 458 phosphorylation of PI3K p85 induced by vascular endothelial growth factor (VEGF)-C, platelet-derived growth factor (PDGF-BB) and insulin-like growth factor (IGF)-1, respectively. AGS cells were treated as in Fig. 4. Western blot analysis was applied to detect the Tyr 458 phosphorylation of PI3K p85. Within 5 min after adding the growth factors to culture medium, phosphorylation of PI3K p85 increased significantly (panel A, Ad-LacZ + VEGF-C group; panel B, Ad-LacZ + PDGF-BB group; panel C, Ad-LacZ + IGF-1 group) and the phosphorylation was inhibited by pre-infecting the cells with Ad-PKG II and stimulating the enzyme with 8-pCPT-cGMP (panel A, Ad-PKG II + cGMP + VEGF-C groups; panel B, Ad-PKG II + cGMP + PDGF-BB groups; panel C, Ad-PKG II + cGMP + IGF-1 groups). The results shown are representative of three separate experiments.

VEGF, PDGF and IGF-1 and the inhibition of PKG II on this process. The results showed that treatment with $100 \mathrm{ng} / \mathrm{ml}$ of VEGF-C, PDGF-BB and IGF-1 caused an increase of Tyr 458 phosphorylation of p85 and PKG II inhibited the phosphorylation processes (Fig. 5).

\section{Discussion}

RTKs are crucial in the regulation of critical cell processes, including proliferation and differentiation, cell survival and metabolism, cell migration and cell-cycle control. Numerous diseases result from genetic changes or abnormalities that alter the activity, abundance, cell distribution or regulation of RTKs. Mutations in RTKs and aberrant activation of their intracellular signaling pathways have been associated with various diseases such as diabetes, inflammation, severe bone disorders, arteriosclerosis and angiogenesis, particularly with regard to cancer (3). Therefore, inhibiting the activation/activity of these RTKs is crucial in tumor suppression.

EGFR exists on the cell surface. Overexpression and mutation of EGFR often occurs in most cancers (23) and patients with overexpression of EGFR usually have a poor prognosis (24). The activating process of EGFR includes the phosphorylation of its intracellular domain and different phosphorylation sites are associated with different signal pathways. For example, phosphorylation of Tyr 1068 and 1086 on EGFR is associated with the MAPK/ERK-mediated pathway (25). Previously, we showed that PKG II inhibits the EGF-induced activation of the key signal transduction components in the MAPK/ERK-mediated pathway and inhibits the phosphorylation/activation of EGFR induced by EGF $(19,20)$, revealing that PKG II exerts an inhibitory effect on TK activity of EGFR and the consequent inhibition of EGF/EGFR-mediated signal transductions.

The VEGF family comprises the members VEGF-A, VEGF-B, VEGF-C, VEGF-D, VEGF-E, PLGF-1 and PLGF-2. These members are important signaling proteins involved in tumor growth and angiogenesis. The main receptors, VEGFR1 and VEGFR2, are responders of VEGFs. VEGF binds mainly with VEGFR2 and the receptor exhibits robust protein-tyrosine kinase activity in response to its ligands and is the predominant mediator of VEGF-stimulated endothelial cell migration, proliferation, survival and enhanced vascular permeability (26). A previous study has shown that VEGF expression in gastric cancer was increased and was associated with an increase of blood vessel density and invasion as well as metastasis of lymph node, bone marrow and other tissues (27). When VEGF binds with VEGFR2, it induces the dimerization of VEGFR2 that leads to autophosphorylation and activation of the receptor. Major phosphorylation sites on VEGFR2 include Tyr 951, 1054, 1059, 1175 and 1214 (28). Our results showed that in AGS cells, VEGF-C induced the phosphorylation of Tyr 951 on VEGFR2 and PKG II inhibited the phosphorylation process. This suggests that PKG II is able to inhibit the activation of other RTKs, with the exception of EGFR.

PDGFs consist of the amino acid chains, $\mathrm{A}$ and $\mathrm{B}$, which dimerize to form the isoforms PDGF-AA, PDGF-AB and PDGF-BB. Of these, PDGF-BB stimulates cells to enter the G1-S phase and proliferate (29). The PDGFR family consists of PDGFR $\alpha$ and PDGFR $\beta$ and previous studies (30-33) have shown that PDGFR expression increased in several cancers including liver, pancreatic, colon and gastric cancer. Similar to the activation of EGFR and VEGFR, the activation of PDGFR by PDGFs includes the binding of PDGFs with the extracellular domain of the receptor, with the consequent phosphorylation of intracellular domains of the receptor and Tyr 751 being one of the phosphorylation sites (34). Our results have demonstrated that in the AGS gastric cancer cell line, PDGF-BB induced the phosphorylation of Tyr 751 on PDGFR $\beta$ and PKG II inhibited the phosphorylation process, providing 
further evidence to identify PKG II as a cancer inhibitor by suppressing the activation of RTKs.

IGFR is a tetramer comprising $\alpha$ and two $\beta$ chains. The intracellular part of $\beta$ chains has tyrosine kinase activity. IGF-1 and -2 are capable of binding with $\alpha$ chains and cause activation of the kinase. The phosphorylation of Tyr 1161 on the receptor is an important event for the activation (35). We assessed anti-phospho-IGF-1R (Tyr 1161) to detect the phosphorylation/activation of IGF-1R and observed that in AGS cells, PKG II inhibited the activating effect of IGF-1R on its receptor. Findings of a previous study showed that IGF-1R is widely expressed in cancer tissues, including renal, colon and gastric cancer (11). In cancer cells, IGF-1R is able to inhibit apoptosis, stimulate vasculogenesis and angiogenesis, regulate migration and promote cell adherence (36). IGF-1R has become a crucial target gene in cancer therapy. Our results showed that PKG II inhibited the activation of IGF-1R, confirming the potential cancer inhibitory effect of this protein kinase by inhibiting RTK activity as well as indicating that PKG II inhibits the activation of RTK with structure difference (a tetramer but not dimer).

In conclusion, our results have demonstrated that PKG II exerts an inhibitory effect on the activation of key RTK members. This suggests that PKG II exerts wide range inhibition on tumor cells. However, more studies are required to confirm this kinase as a potential tumor suppressor.

\section{Acknowledgements}

This study was supported by the National Natural Science Foundation of China (nos. 81272755,31040002 and 81201959); The Innovation Grant of Jiangsu University.

\section{References}

1. Robinson DR, Wu YM and Lin SF: The protein tyrosine kinase family of the human genome. Oncogene 19: 5548-5557, 2000.

2. Zwick E, Bange J and Ullrich A: Receptor tyrosine kinase signalling as a target for cancer intervention strategies. Endocr Relat Cancer 8: 161-173, 2001.

3. Lemmon MA and Schlessinger J: Cell signaling by receptor-tyrosine kinases. Cell 141: 1117-1134, 2010.

4. Choura M and Rebaï A: Receptor tyrosine kinases: from biology to pathology. J Recept Signal Transduct Res 31: 387-394, 2011.

5. Zhang H, Berezov A, Wang Q, et al: ErbB receptors: from oncogenes to targeted cancer therapies. J Clin Invest 117: 2051-2058, 2007.

6. Stuttfeld E and Ballmer-Hofer K: Structure and function of VEGF receptors. IUBMB Life 61: 915-922, 2009.

7. Holmes K, Roberts OL, Thomas AM and Cross MJ: Vascular endothelial growth factor receptor-2: structure, function, intracellular signalling and therapeutic inhibition. Cell Signal 19 2003-2012, 2007.

8. Suzuki S, Dobashi Y, Hatakeyama Y, et al: Clinicopathological significance of platelet-derived growth factor (PDGF)-B and vascular endothelial growth factor-A expression, PDGF receptor- $\beta$ phosphorylation, and microvessel density in gastric cancer. BMC Cancer 30: 659-668, 2010.

9. Hartog H, Wesseling J, Boezen HM and van der Graaf WT: The insulin-like growth factor 1 receptor in cancer: old focus, new future. Eur J Cancer 43: 1895-1904, 2007.

10. Ouban A, Muraca P, Yeatman T and Coppola D: Expression and distribution of insulin-like growth factor-1 receptor in human carcinomas. Hum Pathol 34: 803-808, 2003.

11. Cook AL and Haynes JM: Protein kinase G II-mediated proliferative effects in human cultured prostatic stromal cells. Cell Signal 16: 253-261, 2004

12. Cook AL and Haynes JM: Phosphorylation of the PKG substrate, vasodilator-stimulated phosphoprotein (VASP), in human cultured prostatic stromal cells. Nitric Oxide 16: 10-17, 2007.
13. Chiche JD, Schlutsmeyer SM, Bloch DB, et al: Adenovirus-mediated gene transfer of cGMP-dependent protein kinase increases the sensitivity of cultured vascular smooth muscle cells to the antiproliferative and pro-apoptotic effects of nitric oxide/cGMP. J Biol Chem 273: 34263-34271, 1998.

14. Hood $\mathrm{J}$ and Granger HJ: Protein kinase G mediates vascular endothelial growth factor-induced Raf-1 activation and proliferation in human endothelial cells. J Biol Chem 273: 23504-23508, 1998.

15. Swartling FJ, Ferletta M, Kastemar M, et al: Cyclic GMP-dependent protein kinase II inhibits cell proliferation, Sox9 expression and Akt phosphorylation in human glioma cell lines. Oncogene 28: 3121-3131, 2009.

16. Wang R, Kwon IK, Thangaraju M, et al: Type 2 cGMP-dependent protein kinase regulates proliferation and differentiation in the colonic mucosa. Am J Physiol Gastrointest Liver Physiol 303: G209-G219, 2012.

17. Yang SQ, Chen YC, Wang Y, et al: Expression of cGMP dependent protein kinase II in cancer cell lines was obviously decreased. J Jiangsu Univ (Medicine edition) 18: 1-5, 2008.

18. Chen YC, Ren F, Sang JR, et al: Type II cGMP-dependent protein kinase inhibits proliferation of the gastric cancer cell line BGC-823. Mol Med Rep 3: 361-366, 2010.

19. Wu Y, Chen Y, Qu R, et al: Type II cGMP-dependent protein kinase inhibits EGF-triggered signal transduction of the MAPK/ERK-mediated pathway in gastric cancer cells. Oncol Rep 27: 553-558, 2010.

20. Lan T, Chen Y, Sang J, et al: Type II cGMP-dependent protein kinase inhibits EGF-induced MAPK/JNK signal transduction in breast cancer cells. Oncol Rep 27: 2039-2044, 2012.

21. Fournier NM, Lee B, Banasr M, et al: Vascular endothelial growth factor regulates adult hippocampal cell proliferation through MEK/ERK- and PI3K/Akt-dependent signaling. Neuropharmacology 63: 642-652, 2012.

22. Pratsinis $\mathrm{H}$ and Kletsas D: PDGF, bFGF and IGF-I stimulate the proliferation of intervertebral disc cells in vitro via the activation of the ERK and Akt signaling pathways. Eur Spine J 16: 1858-1866, 2007.

23. Quatrale AE, Porcelli L, Silvestris N, et al: EGFR tyrosine kinases inhibitors in cancer treatment: in vitro and in vivo evidence. Front Biosci 16: 1962-1972, 2011.

24. Normanno N, Bianco C, De Luca A, et al: Target-based agents against ErbB receptors and their ligands: a novel approach to cancer treatment. Endocr Relat Cancer 10: 1-21, 2003.

25. Oda K, Matsuoka Y, Funahashi A and Kitano H: A comprehensive pathway map of epidermal growth factor receptor signaling. Mol Syst Biol 1: 2005.0010, 2005.

26. Hicklin DJ and Ellis LM: Role of the vascular endothelial growth factor pathway in tumor growth and angiogenesis. J Clin Oncol 23: 1011-1127, 2005.

27. Gretschel S, Astrosini C, Vieth M, et al: Markers of tumor angiogenesis and tumor cells in bone marrow in gastric cancer patients. Eur J Surg Oncol 34: 642-647, 2008

28. Koch S and Claesson-Welsh L: Signal transduction by vascular endothelial growth factor receptors. Cold Spring Harb Perspect Med 2: a006502, 2012.

29. Heldin CH: Structural and functional studies on platelet-derived growth factor. EMBO J 11: 4251-4259, 1992.

30. Li ZF, Su YF, Chen XP: Expression of platelet-derived growth factor receptor in hepatocellular carcinoma and portal vein tumor thrombus. Acta Academiae Medicinae Qingdao Universitatis 44: 307-311, 2008 (In Chinese).

31. Luo HG, Ding YW, Ma TX, et al: Study on the correlation between flt-1, bFGFR, PDGFR and tumor biology in pancreatic carcinoma. Zhonghua Xiao Hua Wai Ke Za Zhi 1: 253-255, 2002 (In Chinese).

32. Zhu HT, Han J and Ma L: Expression and clinical significance of PDGFRalpha and PDGFRbeta in colorectal cancer. Ai Zheng 27: 654-660, 2008 (In Chinese).

33. Liu DC, Li RG, Zhou JP, et al: Relationship between the expression of PDGF and PDGFR and MVC in the gastric carcinoma. Zhongguo Lin Chuang Yi Sheng 5: 1061-1062, 2003 (In Chinese).

34. Board R and Jayson GC: Platelet-derived growth factor receptor (PDGFR): a target for anticancer therapeutics. Drug Resist Updat 8: 75-83, 2005.

35. Jones JI and Clemmons DR: Insulin-like growth factors and their binding proteins: biological actions. Endocr Rev 16: 3-34, 1995.

36. Neid M, Datta K, Stephan S, et al: Role of insulin receptor substrates and protein kinase C-zeta in vascular permeability factor/vascular endothelial growth factor expression in pancreatic cancer cells. J Biol Chem 279: 3941-3948, 2004. 